Running head: HOW WE SPEAK ABOUT SOCIAL KINDS

*****In press at Child Development. This version has not been copy-edited and may not reflect the final version as published at Child Development.*****

Does It Matter How We Speak About Social Kinds? A Large, Pre-Registered, Online Experimental Study of How Language Shapes the Development of Essentialist Beliefs 


\begin{abstract}
A problematic way to think about social categories is to essentialize them-to treat particular differences between people as marking fundamentally distinct social kinds. From where do these beliefs arise? Language that expresses generic claims about categories elicits some aspects of essentialism, but the scope of these effects remains unclear. The present study $(N=204$, ages 4.5-8 years, recruited predominantly from the United States and the United Kingdom to participate online in 2019) found that generic language increases two critical aspects of essentialist thought: Beliefs that (1) category-related properties arise from intrinsic causal mechanisms and (2) category boundaries are inflexible. These findings have implications for understanding the spread of essentialist beliefs across communities and the development of intergroup behavior.
\end{abstract}

Keywords: essentialism, generic language, social categorization, cognitive development, intergroup behavior 


\section{Does It Matter How We Speak About Social Kinds? A Large, Pre-Registered, Online Experimental Study of How Language Shapes the Development of Essentialist Beliefs}

When a child hears, "girls love pink," "girls wear dresses," "girls just don't like math," and so on, they learn (or mislearn) more than information about colors, clothing and achievement - they learn that there is something about being a girl that fundamentally determines what a person is like. How profound are these effects of language? Children come to view some of the categories to which people belong — like gender — as marking fundamentally distinct kinds of people: people who are intrinsically different from one another, down to their essential core (Gelman, 2003; Haslam, Rothschild, \& Ernst, 2000; Hirschfeld, 1996). Here we examined how these beliefs are fostered by commonplace patterns in language - particularly, generic descriptions of categories (saying that "girls love pink" instead of that a specific girl does so). To test this, we conducted a high-powered, pre-registered experiment of children via a new webcam-based online laboratory, testing how language shapes children's beliefs about the meaning of otherwise arbitrary groups of people.

\section{Languages Shapes Beliefs about Categories}

A particularly problematic way to think about social categories is to essentialize them (Allport, 1954; Hirschfeld, 1996; Leslie, 2017; Rothbart \& Taylor, 1992). For example, a person with an essentialist view of race thinks that people of the same race are fundamentally similar to one another and intrinsically different from people of a difference race, that someone's race determines (from even before birth) what they will be like, and that differences between racial groups are absolute, natural, and inevitable (Hirschfeld, 1996; Mandalaywala, Ranger-Murdock, Amodio, \& Rhodes, 2019). These beliefs are problematic because they lead people to accentuate the differences between groups (Prentice \& Miller, 2007) and assume that differences they see- 
including those related to status, wealth, achievement, or power, for example — reflect the essential capabilities or worth of the groups and their members, instead of more extrinsic or structural factors (Mandalaywala, Amodio, \& Rhodes, 2017). It is perhaps unsurprising, then, that social essentialism is associated with a range of problematic inter-group phenomena, including stereotyping (Yzerbyt et al., 2001), prejudice (Haslam et al., 2002), decrements in memory for out-group faces (e.g., in the case of race; Gaither et al., 2014), perceptions of increased social distance between members of different groups (Diesendruck \& Menaham, 2015), endorsement of a hierarchical status quo (Mandalaywala et al., 2015), reduced sharing of resources (Rhodes et al., 2017), and decreased motivation to interact with members of other groups (Pehrson, Brown, \& Zagefka, 2009).

Children have the capacity to think in essentialist terms by ages three and four (Gelman, 2003); for instance, young children expect that a baby born to tiger parents will grow up to be a ferocious tiger, even if it is raised by a community of peaceful sheep (Gelman \& Wellman, 1991; Waxman, Medin, \& Ross, 2007). Such findings suggest that children view the behavior and potential of individual animals as determined by powerful, innate, and stable category “essences." Whereas essentialist theories of the natural world reflect cognitive biases—not objective truths (Mayr, 1982, 1988; Leslie, 2013; Gelman \& Rhodes, 2012) — they can nonetheless sometimes license correct and useful inferences (Gelman \& Markman, 1986). For example, it is helpful to assume that a tiger will be ferocious, even if one hasn't encountered that particular tiger before. Even within the biological domain, however, essentialized theories of categories can have problematic consequences, leading people to discount the natural variability present within biological categories and impeding scientific reasoning (Gelman \& Rhodes, 2012; Foster-Hanson \& Rhodes, 2019; Shtulman \& Schulz, 2008). 
Whereas the capacity for essentialist thought emerges early, children do not automatically apply an essentialist lens to the social world (for a review, see Rhodes \& Mandalaywala, 2017). Taking race as an example, children develop essentialist beliefs about race slowly over the course of childhood (often between ages 5-10; Kinzler \& Dautel, 2012; Rhodes \& Gelman, 2009; Mandalaywala et al., 2018). Critically, whether and when children develop essentialist views of race depends on their own racial group membership (Kinzler \& Dautel, 2012; Roberts \& Gelman, 2016); the diversity of their neighborhood, schools, and communities (Mandalaywala et al., 2018; Rhodes \& Gelman, 2009; see also Deeb, Segall, Birnbaum, Ben-Eliyahu, \& Diesendruck, 2011; Smyth, Feeney, Eidson, \& Coley, 2017); and the political and social beliefs of their parents (Rhodes \& Gelman, 2009; see also Segall, Birnbaum, Deeb, \& Diesendruck, 2015). Which social groupings people view in essentialist terms also varies by culture and historical time — sometimes race, sometimes gender, sometimes religion, caste, ethnicity, geography, and so on (Hirschfeld, 1996; Rhodes \& Mandalaywala, 2017). Although children possess early developing capacities for essentialist thought, cultural cues shape how (and when) they map these beliefs onto particular social divisions in their environment.

One potent cue that appears to guide the mapping of these beliefs is language. When children hear abundant generic claims about particular social groupings - claims that describe categories as abstract wholes, such as "girls don't like math," "Italians eat pasta," or "Hispanics live in the Bronx" - they treat those ways of grouping people as more meaningful than they would otherwise (that is, compared to if they had heard only more limited descriptions of particular category members, such as, "this girl doesn't like math," "these Italians eat pasta," or "this Hispanic family lives in the Bronx"; Foster-Hanson, Leslie, \& Rhodes, 2019; Gelman, Ware, \& Kleinberg, 2010; Segall et al., 2015). Indeed, parents' use of generic language is 
associated with the development of their children's essentialist beliefs. As one example, Segall et al. (2015) found that parents' use of generic language in reference to ethnic categories (e.g., "Arabs") predicted the extent to which children reported essentialist beliefs about those categories. In this case, the form of parents' language in reference to social categories (whether it included generics or not) was a stronger predictor of children's beliefs than the content that parents communicated about the categories themselves. Relatedly, Gelman et al. (2004) found associations between mothers' use of generic language about gender (e.g., "girls," "boys") and children's own use of these terms. More generally, parents tend to use generics in domains in which they themselves hold essentialist beliefs about category structure (e.g., for animal species) more often than in domains in which they view categories as less coherent and stable (e.g., for artifacts, Gelman \& Tardif, 1998; Gelman et al., 1998).

Though compelling, studies documenting correlations between parental language and children's concepts cannot isolate the causal role of generic language in the development of social essentialism. To probe this causal mechanism, Rhodes, Leslie, and Tworek (2012) conducted a series of experimental studies to see if generic language would elicit essentialist beliefs about a novel social category for which children would not have essentialist beliefs at the start (see also Gelman, Kleinberg, \& Ware, 2010). In their study, Rhodes, et al. (2012) introduced children (ages 4-5) to a new made-up group of people called "Zarpies." The “Zarpies" were diverse in appearance (i.e., with respect to race, gender, and age), so if a child just looked at the group, it would appear as if members had been placed together arbitrarily, rather than as a product of some fundamental similarity or "essential core" shared among them. Therefore, baseline levels of essentialism were intended to be very low (close to zero) for this category in the absence of generic language. Children were introduced to Zarpies through 
storybooks that showed pictures of Zarpies one at a time; importantly, each picture was accompanied by a narrated description that either contained generics (e.g., "Look at this Zarpie! Zarpies sleep in tall trees.”), or didn't (e.g., "Look at this Zarpie! This Zarpie sleeps in tall trees"). Many of the properties described in the storybook were designed to be unusual (e.g., “...draws stars on her knees," “...really doesn't like ice cream”) — thus further discouraging children from treating these properties as generalizable, innate, or stable in the absence of generic language (indeed, the tendency to treat these properties as individual and idiosyncratic at baseline was confirmed in various control conditions of the experiments).

Corroborating the correlations between generic language and essentialism found in studies of parental language (Segall et al., 2015), children who heard Zarpies described with generic language later viewed the category in more essentialist terms compared to children who heard specific language, thus demonstrating the power of generic language to elicit essentialist beliefs about social categories. While the effect sizes were modest, these studies show that even a small amount of generic language (presented in a 16-page storybook that was read to children 2-4 times, depending on the experiment) was sufficient to lead children to develop essentialist beliefs about a new perceptually diverse group when they wouldn't otherwise (as confirmed in the control conditions). Further, the effects of the language manipulation on children's essentialist beliefs were documented several days after children heard the storybooks, indicating that generics did not just prime essentialist views in the moment, but rather, shaped how children learned to think about the new social group that they encountered. For categories children encounter in their daily lives (e.g., gender categories, Gelman et al., 2004), the initially modest effects of generic language could likely compound over time. Further, generics not only shape a listener's beliefs; they also reflect a speaker's thoughts. Indeed, parents who themselves hold 
essentialist beliefs about categories produce more generics in conversation with their children (Gelman \& Roberts, 2017; Rhodes et al., 2012; Segall et al., 2015). Together, correlational studies of parental language (Segall et al., 2015; Gelman et al., 2004) and experimental studies (Gelman et al., 2010; Rhodes et al., 2012, 2017) identify generic language as a critical mechanism that shapes the development of essentialist beliefs.

\section{How Deep Are These Effects?}

And yet, a number of important questions remain about the scope and implications of these effects. Essentialism is comprised of a number of inter-related beliefs. For example, the particularly pernicious views of race described earlier include the beliefs that (a) people of the same race are fundamentally similar (i.e., that categories are homogeneous), (b) category-based similarities and differences are caused by intrinsic mechanisms, (c) someone's race determines (from before birth) what they will be like (i.e., that differences are innate and stable), and (d) differences between groups are absolute, natural, and inevitable. It is possible to separate out these beliefs - for example, one might think that people of the same race are fundamentally similar to each other, but not believe that this is the natural state of the world or that group-based disparities arise from intrinsic causal mechanisms (Gelman, 2003; Noyes \& Keil, 2019; Rhodes \& Mandalaywala, 2017; Rhodes \& Moty, 2020; Vasilyeva, Gopnik, \& Lombrozo, 2018). Instead, these group patterns might be understood in terms of the structural and historical processes that led to them. Thus, the different components of people's beliefs that fall under the umbrella of essentialism need not always relate to one another.

In previous research on generics and social essentialism, various measures of children's concepts have been combined to yield composite scores of essentialism that collapse across multiple dimensions, without sufficient statistical power to examine the components separately. 
Thus, it is possible that generics shape some aspects of children's beliefs (e.g., the idea that the category-related properties described by generics are generalizable, related to the idea that categories are homogeneous) but not others (e.g., the beliefs that category-based regularities are intrinsic, innate, and inevitable, or that category boundaries are absolute and natural; Noyes \& Keil, 2019; Noyes \& Keil, 2020; Saul, 2017; Vasilyeva et al., 2018).

If this is indeed the case, it would have important implications not only for how language shapes conceptual development, but also for some of the proposed social applications of this work. For example, consider the generic claim, "Girls get higher grades in English than math." If one interprets this statement as just providing generalizable information (e.g., that more girls get higher grades in English), this might not itself be problematic. What really seems to matter is the causal attribution for this pattern. If one interprets this to mean that girls have a natural and inherent knack for English and deficiency in math, consistent with an essentialist framework, then this could lead to problematic stereotyping and discrimination (e.g., withholding from girls opportunities to succeed in math). But, if one interprets this statement as meaning that people have previously (and unfairly) discouraged girls in math, then this could instead lead to beneficial consequences - perhaps support for programs to rectify this inequality (Noyes \& Keil, 2019; Rizzo, Elenbaas, \& Vanderbilt, 2020; Vasilyeva et al., 2018). Similarly, if one takes the statement to describe absolute associations between categories and features (e.g., that a girl could not sometimes be better at math than English), this would be more problematic than if one interprets it only as a statistical association that does not constrain potential in this way. In other words, the problematic nature of generics seems to depend, at least somewhat, on which components of essentialism generics elicit—only beliefs that features are generalizable, or 
beliefs that category-related features are caused by intrinsic mechanisms and that these relations are absolute (and cannot be otherwise).

Thus, one goal of the present project was to identify whether or not generics elicit aspects of essentialist thought that go beyond the belief that category features are generalizable. Whereas some prior work has found that generics lead children to assume that the patterns described are explained by intrinsic causes (Cimpian \& Markman, 2009, 2011; Gelman et al., 2010; Rhodes et al., 2012, 2017; Foster-Hanson et al., 2019; Foster-Hanson \& Rhodes, 2020), others have found effects only on whether people think the features described by generics are generalizable (Noyes 2019, 2020, see also Vasilyeva et al., 2018), necessitating focused work on this question.

To address this issue, the present study considered the effects of generic language on various distinct components of children's beliefs as they learned about a new social group. In our exploration of these components, we opted not to include a measure of whether children think features are generalizable for the reasons indicated above. That is, the belief that features are generalizable might not always itself reflect essentialism (as people can think that category members share features due to extrinsic causes, as in the example above in which people could think that girls achieve less in math because of historic discrimination, not inherent potential). Secondly, thinking of features as generalizable might itself not be problematic; rather, as described above, the problematic consequences seem to depend on whether people endorse intrinsic mechanisms (e.g., thinking that girls are inherently worse at math) and constrain potential (e.g., thinking that a girl cannot be good at it). Instead, we used two common measures of whether children think that features described with generics reflect inherent causes - an explanation task (Cimpian \& Markman, 2009, 2011; Rhodes et al., 2012) and a switched-at-birth task (which specifically tests if children think category-related features are inherited and stable; 
e.g., Hirschfeld, 1996; Taylor et al., 2009) — and one measure testing whether children think the relation between categories and their described features is absolute (and cannot be otherwise; see Taylor, Rhodes, \& Gelman, 2009; Rhodes et al., 2017). In doing so, we sought to empirically test which aspects of essentialism are elicited by generics, a critical question both for conceptual development and for considerations of the social implications of generics for the development of children's social cognition and behavior.

\section{The Present Study}

We tested these questions in a pre-registered unmoderated remote experimental study (see Rhodes et al., 2020; Scott \& Schulz, 2017; Scott et al., 2017). The study was entirely selfadministered; materials consisted of animations and narrations, and children completed the study remotely on their own time, without interacting with an experimenter. By automating the study in this way, we could achieve a high level of experimental control and facilitate replicability (for the benefits of unmoderated remote research for facilitating robust and reliable science, see Rhodes et al., 2020). With this approach, we recruited a larger, more geographically diverse sample in a much more efficient manner than could have been accomplished through traditional in-person testing; this increased our power to obtain precise estimates of the effect of generic language on each measure of essentialism, as well as to test for other covariates (e.g., child age). Also, though participation in the study necessitated access to a computer with WiFi and a webcam (a non-negligible barrier to entry; see Lourenco \& Tasimi, 2020), this online method allowed us to recruit a sample of children from neighborhoods with a high level of diversity with respect to population size, percent of racial-ethnic diversity, and median income. These metrics of diversity — though certainly not all-encompassing (in terms of participant race-ethnicity, for example, our sample was still quite homogenous) — are particularly important within the context 
of our study given that social essentialism follows different developmental trajectories as a function of children's local environments (e.g., Rhodes \& Gelman, 2009; Mandalaywala et al., 2019). Thus, the ability to draw from a sample that did not come from a single geographic area had the potential to increase the generalizability of our findings (or to test for boundaries on these effects).

The original studies in Rhodes et al., 2012 focused on the ages at which social essentialist beliefs first emerge (ages 4-5), but here we took advantage of the efficiency of our platform to extend the age-range upward to test if the implications of language for children's beliefs remain consistent, increase, or decrease across age. While essentialist beliefs have sometimes been found to decrease across childhood (e.g., Astuti et al., 2004; Taylor, 1996; suggesting that linguistic mechanisms may less easily elicit these beliefs), children also often hold stronger essentialist beliefs across childhood about the particular categories for which adults in their community hold essentialist beliefs (Rhodes \& Gelman, 2009), suggesting instead that these linguistic mechanisms could continue to shape children's beliefs across age (Smyth et al., 2017; Birnbaum, Deeb, Segall, Ben-Eliyahu, Diesendruck, 2010; Deeb et al., 2011; Diesendruck, Goldfein-Elbaz, Rhodes, Gelman, \& Neumark, 2015).

\section{Method}

\section{Participants}

Participants were recruited to the online lab ([blinded for peer review]) via a variety of methods, including community outreach efforts, social media, and advertisements on Facebook and parenting podcasts. We shared the link to the online lab broadly beginning in May 2019, and anyone who landed on the page with a child in the age-range of this study (4.5-8 years) was eligible to participate until November, when we closed the study. Additionally, a subset of our 
sample (34\%) included children recruited through Prolific, a research platform based in the United Kingdom that posts studies for a registered pool of adult and child participants. Parents provided their child's birthdate, gender, race, primary language, school level, and zip code.

As per our pre-registration ([blinded for peer review]) we aimed to collect a sample of 200 children (approximately 100 per condition). This sample size was informed by a power analysis based on Rhodes et al., 2012, but then increased to allow us to detect changes across age, to identify the effects of a briefer language manipulation on essentialist beliefs (as here children heard the story containing the language manipulation only once, instead of 2-4 times as in previous research), to examine the various components of essentialism separately, and to explore possible regional variation in our findings. We specified in our pre-registration that the age-range would include children ages 4.5-7.99, but because of a programming glitch, children ages 4.5-8.99 were able to participate. Because we had no theoretical reason to cut off the agerange, we decided to retain these slightly older children in the final sample. We also intentionally oversampled because we did not have a good way to estimate in advance the number of participants who might need to be excluded due to technical difficulties, parental interference, and so on.

With consent, children's participation in the study was recorded via their computer's webcam (and uploading a video at the end was required for inclusion in data analysis). The final sample included 204 children $\left(M_{\text {age }}=6.36, S D_{\text {age }}=1.17\right.$; range $\left.=4.50-8.87\right)$. An additional two children began the experiment and uploaded a video but completed less than $50 \%$ of the test trials; as specified in our pre-registration, these data were excluded from analyses.

These 204 participants were evenly balanced in terms of gender ( $50 \%$ female; $50 \%$ male) and included participants from a range of racial backgrounds (73.04\% White, 5.39\% Black, 
$3.43 \%$ Hispanic, $5.39 \%$ Asian, $12.75 \%$ multi-racial). Due to the nature of our data collection, our sample reflected a high degree of geographic diversity: $75.00 \%$ of children were recruited from the United States, 20.59\% were recruited from the United Kingdom, 2.94\% were recruited from Canada, and less than 1\% were recruited from Mexico, Australia, and New Zealand (see Figure 1). Even within the US, our sample contains a high degree of geographic spread. Based on 2019 estimates from United States census data, the 153 US participants who provided their zip code came from areas that varied substantially in population size $(M=31,953$ residents, $S D=18,125$; range $=775,89,453)$; proportion of Black, Asian, and non-White Hispanic residents $(M=$ $33.75 \%, S D=24.89 \%$; range $<1 \%, 93 \%)$; and median family income $(M=\$ 97,916, S D=$ $\$ 41,995$; range $=\$ 36,933-\$ 215,405)$. Despite the neighborhood diversity reflected in these metrics, White children and children from higher income neighborhoods were overrepresented in the sample. For results broken down by country (i.e., United States versus United Kingdom), as well as for more information about our neighborhood-level diversity metrics, see the Supplementary Online Materials.

\section{Procedure}

The only three technical functionalities required for participation were (1) a webcam, (2) internet (with a sufficiently strong connection to upload a successful video at the end of the session), and (3) a Chrome or Firefox web browser. To begin the study, parents selected the study link and then clicked to allow the website to activate their webcams.

At the start of the study, parents provided verbal informed consent and children provided verbal assent, following procedures approved by the IRB\# FY2016-760. Then, parents and children were given instructions about how to navigate through the study — children were encouraged to click on answers themselves, or to point to their answers and have parents click 
for them if they were not able to. We encouraged parents not to provide any feedback to children during the study. At this point, children began the study, which consisted of a series of short videos and questions animated in Keynote, exported as movie files, and then programmed in Qualtrics. All stimuli files for the manipulation and test items may be viewed at [blinded for peer review].

As in the original study (Rhodes et al., 2012), we first introduced children to a novel social group called "Zarpies" via an illustrated storybook. The content of the storybook was identical to Rhodes et al., 2012: it contained 16 pages, each of which showcased a unique Zarpie displaying a particular physical or behavioral property (e.g., "likes to eat flowers" or "sleeps in tall trees") that was narrated aloud (this time by a recorded narrator, instead of a live experimenter). The language used throughout the story varied based on the condition to which participants were randomly assigned: children in the Generic condition heard generic descriptions of Zarpies (e.g., "Look at this Zarpie! Zarpies like to eat flowers"), whereas children in the Specific condition heard language that referenced only the specific Zarpie on the page (e.g., "Look at this Zarpie! This Zarpie likes to eat flowers"). Children listened to the story aloud only once - a weaker manipulation than that used in the original study, where children heard the story 2-4 times, across a period of several days. After listening to the story, children were asked to answer a series of questions about Zarpies.

\section{Measures}

Our measures were comprised of three types of essentialism items (explanation items, flexibility items, and inheritance items), as well as two novel tasks probing intergroup cognition and behavior (resource allocation and expectation of reciprocity tasks). The design and composition of the essentialism items differed somewhat from previous work (Rhodes et al., 
$2012 ; 2017)$. As noted in the Introduction, we opted not to include measures of whether children think the properties described by generics are generalizable (previously tested with induction items) because these - on their own — are weak indicators of essentialist thinking. Instead, we focused on three measures that more clearly reflect essentialist thought (and that are also more likely to be problematic for social attitudes and behavior).

\section{Essentialism measures.}

Intrinsic causal mechanisms (Explanation). The first measure of essentialist beliefs explored the extent to which participants viewed category membership as explaining the development of typical category properties - a central tenant of essentialist thought (Cimpian \& Markman, 2011; Gelman, 2003; Taylor, Rhodes, \& Gelman, 2009). In this task, children were asked a question about a behavior ("Why is this Zarpie jumping over a puddle?") and provided two possible responses inspired by those commonly generated by children in previous researchone that invoked an intrinsic, category-related cause ("Because a lot of Zarpies like jumping over a puddle (scored as ' 1 ')"), and another that invoked an extrinsic, individual reason ("Because he is running a race (scored as '0')’). This paradigm deviated from that used in Rhodes et al., 2012, wherein items were presented as open-ended questions and then coded for the presence of intrinsic and extrinsic explanations; here, we sought to preempt potential discomfort from speaking aloud to a computer screen by having children select, rather than generate, a response (for a similar approach, see Foster-Hanson, Leslie, \& Rhodes, 2019).

Category boundaries as absolute (Flexibility). Our second essentialism measure investigated children's understanding of category boundaries as absolute and inflexible (Gelman, 2003; Rhodes \& Gelman, 2009a, 2009b; Rhodes, Gelman, \& Karuza, 2014; Roberts, Ho, Rhodes, \& Gelman, 2017). Here we tested this as the belief that a category member could only 
display properties associated with its category (and could never display properties not associated with it; similar to Taylor, Rhodes, \& Gelman, 2009). For example, children were told, "Look at this Zarpie. This Zarpie sleeps in a tall tree. Do you think this Zarpie might sometimes sleep in a bed too (scored as '0'), or only in a tree (scored as ' 1 ')?'.

Category features as innate and stable (Inheritance). Our last measure of essentialism tested children's belief in the innate potential of categories (i.e., the heritability of category membership and properties; Gelman, 2003) using a switched-at-birth paradigm (Gelman \& Wellman, 1991; Hirschfeld, 1996; Waxman et al., 2007). As in Rhodes et al., 2012, we described a scenario in which a Zarpie baby was born to a Zarpie mom but raised by a non-Zarpie mom. Then, we asked, "Will this child like ice cream like the non-Zarpie mom (scored as "0"), or not like ice cream like the Zarpie mom (scored as ' 1 ')?". We chose to include one of the switchedat-birth questions from the original study (described above) and one directly asking if category membership is something one possesses "deep down" (e.g., "Is this [one] a Zarpie deep down (scored as '1'), or not a Zarpie deep down (scored as '0')?’).

\section{Inter-group behavior measures.}

Following the essentialism measures, children engaged in two additional tasks: one probing resource allocation decisions, and the other probing expectations of reciprocity. In both measures, children were introduced to a Zarpie and a non-Zarpie; then, children had to decide which target they (i) would offer a resource (e.g., a cookie) to, or (ii) expect to receive a resource from. Each decision to give or expectation to receive a resource from a Zarpie was scored as "1", and decisions to give or expectations to receive from a non-Zarpie was scored as " 0 ". Children made three decisions for each task. 
The addition of these two measures was motivated by Rhodes et al. (2017), which found that inducing essentialist beliefs with generic language also led children to offer fewer resources to members of the newly essentialized kind. We reasoned that the inclusion of the resource allocation measure would allow us to conceptually replicate this effect, while the expectations of reciprocity measure may illuminate a potential mechanism underlying it (i.e., whereby children opt to give fewer resources to Zarpies because they expect to receive fewer in return). Due to time constraints and differences in the testing platform, the details of our resource allocation task differed from the original study (Rhodes et al., 2017); in particular, children in our study were asked to allocate a series of resources to a Zarpie or a non-Zarpie one at a time, whereas in the original study, children were given a number of resources at once (e.g., 4 stickers) and asked how many to designate to a Zarpie.

\section{Debriefing}

After children had completed all measures, families were thanked for their time and participation and provided the opportunity to offer feedback on their study experience. As compensation for participation, families who completed the study received a \$10 Amazon giftcard (or, for participants recruited through Prolific, a digital payment of \$10). Overall, the study took families between 10 and 15 minutes to complete.

\section{Video Coding}

To ensure that the data collected in the online lab were valid - that is, that they captured real children participating, without undue influence from others-all videos were checked for the presence of a child and parent who, together, provided consent to participate. Additionally, $87 \%$ of all study videos were coded in Datavyu (Lingeman et al., 2014) by a trained coder. Of these, $31 \%$ were double-coded by a second coder for reliability. Videos were coded for the presence of 
parent-child interactions (including pointing, verbal feedback, and gesturing) and other environmental distractions (e.g., pets making noise in the background), as well as the relevance of each of these instances. Critically, all audible coded interactions were evaluated for whether or not they interfered with the child's response. Overall, the correlation of interference determinations per participant across primary and reliability coders was excellent $(r=.88)$. Indeed, correlations between coders for trials coded as definitely or potentially containing an interference was high $(r=.75)$, as were correlations between coders for interactions marked as not containing an interference $(r=.75)$.

Notably, the number of interferences was small ( $N=21$ out of 2,492 trials completed by participants with coded videos; less than $1 \%$ of total trials coded), and only one participant experienced interferences on more than $25 \%$ of trials. Because of the low incidence of interference, we chose to retain all trials in our primary analyses. For analyses with interference trials removed, please see Supplementary Online Materials. Our full coding manual for Datavyu processing, as well as descriptive analyses of all of the other measures coded, are available at [blinded for peer review]. Additionally, 53.92\% of families in our sample gave permission for their video to be shared with developmental researchers via Databrary; these are available at [blinded for peer review].

\section{Results}

To examine the effects of language on each component of children's beliefs, we implemented a series of generalized linear mixed-effects models using the lme4 package in R, with experimental condition (Generic, Specific), age (entered as children's exact age at time of test, centered for analyses), and their interaction as fixed effects, and subject and item number as 
random effects. Data and analytic code for these analyses are available at [blinded for peer review].

\section{Essentialism}

Essentialism composite. Replicating previous work (including Rhodes et al., 2012), we first considered the essentialism measures together, as a composite (we subsequently present analyses separately for each measure of essentialism). Consistent with findings from the original study, children endorsed more essentialist beliefs overall after hearing generic than specific language $(B=.48, S E=.13, z=3.59, p<.001)$, see Figure 2. Children in the Generic condition were 1.61 [Wald 95\% confidence interval $(\mathrm{CI})=1.24,2.12$ ] times as likely to endorse essentialist responses than children in the Specific condition. Children's aggregate essentialism scores did not vary by age $(B=.12, S E=.08, z=1.46, p=.14)$, nor as a function of an age by condition interaction $(B=.14, S E=.11, z=1.19, p=.23)$.

Intrinsic causal mechanisms (Explanation). Children in the Generic condition endorsed more intrinsic explanations for Zarpie properties than those in the Specific condition $(B=.83, S E$ $=.22, z=3.77, p<.001 ; O R=2.34, \mathrm{CI}=1.51,3.77)$, see Figure 3. Children also endorsed more essentialist responses with age $(B=.28, S E=.14, \mathrm{z}=2.03, p=.04$; see Figure 4$)$, but there was no interaction between age and condition $(B=.22, S E=.19, z=1.19, p=.23)$.

Category boundaries as absolute (Flexibility). Children in the Generic condition perceived the Zarpie category as more rigid and inflexible (meaning they were more likely to say that a Zarpie could only display features associated with being a Zarpie) than children in the Specific condition $(B=.54, S E=.20, z=2.70, p=.007 ; O R=1.71, C I=1.16,2.59)$, see Figure 5. Effects on this measure did not vary by age $(B=.04, S E=.12, z=.36, p=.72)$, and there was no age by condition interaction $(B=-.08, S E=.17, z=-.50, p=.62)$. 
Category features as innate and stable (Inheritance). Children's beliefs about heritability did not vary by condition $(B=-.09, S E=.26, z=-.34, p=.73)$, age $(B=.05, S E=$ $.16, z=.33, p=.74)$, or the interaction between the two $(B=.42, S E=.23, z=1.84, p=.07)$. For exploratory purposes (given previous work using this measure), we tested the slopes associated with age in each condition. Children's tendency to perceive the novel social category as heritable and stable increased with age in the Generic condition $(B=.45, S E=.16, z=2.83, p=.005)$, but not in the Specific condition $(B=.05, S E=.16, z=.32, p=.75$; see Figure 6$)$.

\section{Inter-group Behavior}

Resource allocation. Replicating prior work from Rhodes et al., 2017, children who heard generic language about Zarpies allocated resources (e.g., cookies) to Zarpies less often than children who heard specific language $(B=-.48, S E=.23, z=-2.09, p=.04$; see Figure 7$)$. Allocation decisions did not vary by age $(B=-.12, S E=.14, z=-.87, p=.39)$, nor was there an interaction between age and condition $(B=.06, S E=.20, z=.28, p=.78)$.

Expectations of reciprocity. Our novel measure of expectations of reciprocity did not vary as a function of condition $(B=-.22, S E=.23, z=-.97, p=.33)$, age $(B=-.23, S E=.14, z=$ $-1.63, p=.10)$, or their interaction $(B=.36, S E=.20, z=1.84, p=.07)$.

\section{Exploratory Analyses of Geographic Variables}

Given the breadth of neighborhood-level diversity present our sample (i.e., with respect to population size, racial-ethnic diversity, and household income) and the documented effects of contextual factors on essentialism (Rhodes \& Gelman, 2009; Mandalaywala et al., 2020), we probed the influence of these neighborhood metrics in a set of exploratory (non-preregistered) analyses. Specifically, in a series of three analyses, we separately tested whether each of these metrics influenced composite levels of essentialism (or interacted with experimental condition). 
Across all three metrics of neighborhood-level diversity, the main effect of generic language on essentialism persisted ( $p$ s $=.003-.012$ ), providing evidence of the generalizability of our effect. Intriguingly, we found a separate main effect of neighborhood racial-ethnic diversity on children's level of essentialism, whereby greater racial-ethnic diversity in children's neighborhoods was associated with lower levels of essentialism overall, regardless of condition $(B=-.88, S E=.45, z=-1.94, p=.05)$. Whereas previous work has found a specific relation between exposure to racial diversity and racial essentialism in particular (Mandalaywala et al., 2020; Rhodes \& Gelman, 2009; Pauker, Tai, \& Ansari, 2020), these findings are the first that we are aware of to suggest possible effects of exposure to diversity on children's more general tendency to develop essentialist beliefs about a new social category. For more details on these exploratory analyses and consideration of other neighborhood variables, see the Supplementary Online Materials.

\section{Discussion}

The present study found that commonplace patterns in language shape the development of children's essentialist beliefs. Children's inferences went far beyond the content of the language that they heard. For example, there is nothing in the sentence, "Zarpies hop over puddles" that directly communicates that a particular Zarpie does so for intrinsic, category-based reasons (e.g., because many Zarpies hate to get wet, instead of simply because he needed to get to the other side) or that this the only way he would deal with a puddle (e.g., that he wouldn't sometimes choose to splash in it instead). Yet, generics - more so than descriptions of specific individuals - increased the likelihood that children would draw these types of inferences.

In the present study, the implications of language for children's beliefs were similar but not identical across measure and age. Overall, generic language led children to endorse more 
intrinsic, category-related explanations and to view category boundaries as more rigid, but not to perceive the features described with generics as inherited (as assessed with the "switched-atbirth" paradigm; however, an exploratory analysis suggested effects on this measure might emerge with age). With respect to our null findings on this last measure, it is possible that children (and younger children in particular) had difficulty comprehending the switched-at-birth paradigm as administered here because unlike previous studies (e.g., Rhodes et al., 2012; Taylor, 1996; Hirschfeld, 1996; Waxman et al, 2007), it did not include embedded comprehension questions and opportunities for the story to be repeated. It is also possible, however, that generic language on its own is not sufficient to lead children to think that category features are inherited, perhaps particularly when children are making judgments about new social groups, as done here (see Foster-Hanson et al., 2019; Gelman et al., 2010). From this perspective, generic language might shape beliefs about heritability only under certain circumstances; for instance; Noyes \& Keil $(2019,2020)$ found that generic language led children and adults to believe that category features were inherited only when they described biological (not culturally determined) properties. One possibility, therefore, is that generics lead children to think that features have intrinsic causes (as shown in the present explanation task; and see Cimpian \& Markman, 2009; 2011; Cimpian \& Salomon, 2014), but not necessarily that they are inherited unless they are accompanied by further information about biology — either that the features specifically have biological origins (as shown in Noyes \& Keil, 2020) or a preconceived notion of a category as biologically determined (e.g., as may be the case for gender categories, see Taylor et al., 2009). The present study found clear effects on two other components of essentialist beliefschildren's endorsements of intrinsic explanations and their beliefs that category-related properties are inflexible. Why do children draw these inferences from generics? These are not 
merely logical interpretations of the generic descriptions. For example, "Zarpies climb tall fences" is compatible with both the interpretation that Zarpies do so because they love to climb and the interpretation that they do so because their town is surrounded by a fence with no door, so they do not have another choice (Vasileyva et al., 2018). Similarly, "Zarpies climb tall fences" could mean that they always and only do that, or that they sometimes climb fences and sometimes walk around them or open their doors.

We suggest that generics elicit essentialism—despite this ambiguity around their meaning-because of how they interact with the conceptual biases that underlie how people (and perhaps especially, young children) make sense of the world. From this perspective, young children recognize that there are many possible ways of classifying people, but view some of these classifications as holding more conceptual weight than others; that is, they expect some ways of categorizing people to mark coherent and objective clusters of people (e.g., gender groups) but other ways of classifying people to be more flexible and context-dependent (e.g., color groups in a classroom; for a review, see Rhodes \& Mandalaywala, 2017). With this expectation in mind, children are on the lookout for cues in their environment as to which ways of classifying people are most stable and meaningful. Generic language provides a powerful cue. By two and a half years of age, children both recognize that generics refer to categories (rather than specific individuals; Gelman \& Raman, 2003) and expect that adults know the right ways to label and categorize things (Jaswal \& Neely, 2006). Thus, generic claims (e.g., "Zarpies hop over fences") can lead children to think that particular groupings (e.g., Zarpies) are informative for making sense of what different people are like because they signal that adults in their community see these categories as meaningful. In this way, generics do not create essentialist thought in children - they cue its application by serving as a signal of how their community sees the world. 
Consistent with this perspective, children respond to generics differently when they come from knowledgeable versus unknowledgeable sources (Moty \& Rhodes, 2019). Also, generics cue essentialist beliefs even when all they do is signal speakers' beliefs that the category is informative - even if they fail to communicate any of the features that category members have in common (Foster-Hanson et al., 2019). Of course, generics are not the only way to elicit essentialism; children might develop essentialist beliefs from their own observations or from other language that directly communicates that properties of a category are intrinsic and shared across members. Nevertheless, generics appear to serve as particularly efficient cues to which types of categories are considered coherent and meaningful within a child's social environment.

This study also corroborated earlier findings of the consequences of subtle features of language for inter-group behavior. As in Rhodes et al. (2017), here generic language (compared to specific language) decreased children's willingness to allocate resources to a member of the Zarpie group. Why exactly generics have this effect on resource allocation remains unclear. Rhodes et al. (2017) proposed that perhaps essentialist beliefs (as triggered by generic language) increase the salience of the category boundary (i.e., between the child participant and Zarpies) as children consider future opportunities for social interaction and reciprocity; by this account, essentialism leads children to consider that members of another category might be unlikely to share with them, thus decreasing their own willingness to share. In the present study, however, generics influenced only children's own willingness to share, not their expectations about who would share with them. Thus, the mechanisms by which generic language and essentialist beliefs shape children's inter-group behaviors will need to be examined in more detail in future work.

The present study suggests that avoiding generic language may be one way to limit the spread of essentialist beliefs and avoid some of their negative consequences for inter-group 
relations (Levy \& Dweck, 1999; Pauker et al., 2010). Yet, it is important not to misinterpret this work as advocating for a "color-blind" approach to social differences (Firebaugh \& Davis, 1998; Plaut, 2002). Note that category labels were given in both conditions here-thus, this work does not suggest that adults should avoid labeling social differences or discussing aspects of social identity that are important in modern society and to people's lives. Instead, we argue that the form used in these types of communications is consequential and can lead children to draw inferences that adult communicators might not intend. Knowing that, in response to generic language, children tend to assume intrinsic causes (as shown by the present explanation items) and infer fixed relationships between categories and features (as shown by the flexibility items) means that these beliefs might need to be addressed directly in discussing social differences with children. For instance, adults may seek to make explicit the historical and structural forces that give rise to social differences, the process by which these forces were created in the first place, and the living reality that differences are not innate or inevitable (e.g., Noyes \& Keil, 2019; Saul, 2017; Vasilyeva et al., 2018).

\section{Unmoderated Remote Research as a Tool for Developmental Science}

This project also illustrated how unmoderated remote research can help advance developmental science (Rhodes et al., 2020). In this work, we used broadly available tools (that do not require programming expertise) to create simple narrated animations of the entire study, including the manipulation and test questions, that allowed children to complete the study independently. This approach facilitates reliability and replication. For example, all of our animated and narrated stimuli are all available on [blinded for peer review], and could be downloaded and used by other researchers in this area (even when testing in-person instead of online), thus making sure that methods are implemented in similar ways across studies and labs. 
Further, this approach eliminates concerns about experimenter mistakes during testing, as well as about possible experimenter biases (in the present study, parents — who sat next to their children during the study - were naturally blind to hypotheses, but if a researcher administered the study using these materials in the future, they could remain blind to which language condition the child received simply by having the child wear headphones during the manipulation phase). If this approach to implementing simple behavioral experiments with children were adopted broadly, it would increase the robustness of these experiments and facilitate the sharing of methods and stimuli for cross-lab replication — a practice that can be challenging for studies that involve elaborate scripted interactions with children that are difficult to fully describe in journal articles (for discussion, see Adolph, Gilmore, \& Kennedy, 2017; Gilmore, Kennedy, \& Adolph, 2018). In addition to enhancing standardization and reproducibility, this approach offers the potential for developmental researchers to efficiently conduct studies that yield more generalizable findings by facilitating sampling with larger and more diverse populations (see Frank et al., 2017; Frank, 2019; Button et al., 2013; Nielson, Haun, Kartner, \& Legare, 2017). Doing so allows testing new theoretical questions about how context, identity, and experience shape development - a particularly important issue when researchers are, as we are here, interested in children's understanding of social diversity itself - as well as more fine-grained analyses of how effects change across age, allowing for new insights into developmental processes. Yet, to capitalize more fully on this potential, future research will be needed to explore how to further increase the accessibility of remote online studies for families from more racially and ethnically diverse backgrounds, as well as for families from lower-income communities and with more limited access to technology (Lourenco \& Tasimi, 2020). 
Whereas remote research is certainly not possible for all studies (e.g., those of motor behavior, Adolph et al., 2003, or that require social interaction with an experimenter, FosterHanson et al., 2019), the present method builds on several others (Scott \& Schulz, 2017; Scott, Chu, \& Schulz, 2017; Sheskin et al., 2020) showing the feasibility of conducting developmental research online. We add to this small (but proliferating) body of studies by highlighting the importance of this approach for research on social cognition in particular, by showing how this approach can be implemented using tools that are broadly available (without extensive programming knowledge) and in a manner that children can complete on their own (without directly interacting with an experimenter via video-conference (a common protocol for online research; see Sheskin et al., 2020), and by extending this approach to more complicated and longer experimental paradigms than have been previously tried with children online. Given recent efforts at replication in related fields (Camerer et al., 2018), the field needs new approaches for conducting experimental developmental science with larger samples and using methods that are easier to share and replicate (for recent efforts in this area, see Chouinard, Scott, \& Cusack, 2019; Databrary, 2012; Frank et al., 2017; Rubio-Fernández, 2019; Scott \& Schulz, 2017; Wood \& Wood, 2019). We think that online research, paired with other best practices for promoting robust science, including pre-registration, ensuring sufficient power, and methods and data sharing (including videos of experimental sessions via Databrary, as we have done here; [blinded for peer review]), has great potential for moving developmental science forward. 


\section{References}

Adolph, K. E., Gilmore, R. O., \& Kennedy, J. L. (2017). Video data and documentation will improve psychological science. Psychological Science Agenda, (/science/about /psa/2017/10/index.aspx).

Allport, G.W. (1954). The Nature of Prejudice. Cambridge, MA: Perseus Publishing.

Astuti, R., Solomon, G. E. A., \& Carey, S. (2004). Constraints on conceptual development. Monographs of the Society for Research in Child Development, 69, 1- 135.

Birnbaum, D., Deeb, I., Segall, G., Ben-Eliyahu, A., \& Diesendruck, G. (2010). The development of social essentialism: the case of israeli children's inferences about jews and arabs. Child development, 81(3), 757-777. https://doi.org/10.1111/j.14678624.2010.01432.x

Button, K. S., Ioannidis, J. P. A., Mokrysz, C., Nosek, B. A., Flint, J., Robinson, E. S. J., \& Munafò, M. R. (2013). Power failure: Why small sample size undermines the reliability of neuroscience. Nature Reviews Neuroscience. https://doi.org/10.1038/nrn3475

Camerer, C. F., Dreber, A., Holzmeister, F., Ho, T. H., Huber, J., Johannesson, M., ... Wu, H. (2018). Evaluating the replicability of social science experiments in Nature and Science between 2010 and 2015. Nature Human Behaviour. https://doi.org/10.1038/s41562-0180399-Z

Chouinard, B., Scott, K., \& Cusack, R. (2019). Using automatic face analysis to score infant behaviour from video collected online. Infant Behavior and Development. https://doi.org/10.1016/j.infbeh.2018.11.004 
Cimpian, A., \& Markman, E. M. (2009). Information learned from generic language becomes central to children's biological concepts: Evidence from their open-ended explanations. Cognition, 113(1), 14-25. https://doi.org/10.1016/j.cognition.2009.07.004

Cimpian, A., \& Markman, E. M. (2011). The Generic/Nongeneric Distinction Influences How Children Interpret New Information About Social Others. Child development, 82(2), 471492. https://doi.org/10.1111/j.1467-8624.2010.01525.x

Cimpian, A., \& Salomon, E. (2014). The inherence heuristic: An intuitive means of making sense of the world, and a potential precursor to psychological essentialism. Behavioral and Brain Sciences, 37(5), 461-480.

Databrary. (2012). The Databrary Project: A video data library for developmental science. New York: New York University. Retrieved from http://databrary.org

Deeb, I., Segall, G., Birnbaum, D., Ben-Eliyahu, A., \& Diesendruck, G. (2011). Seeing isn’t believing: the effect of intergroup exposure on children's essentialist beliefs about ethnic categories. Journal of Personality \& Social Psychology, 101, 1139-1156.

Diesendruck, G., Goldfein-Elbaz, R., Rhodes, M., Gelman, S., \& Neumark, N. (2015).

"Cross-cultural differences in children's beliefs about the objectivity of social categories": Erratum. Child Development, 86(2), 659. https://doi.org/10.1111/cdev.12369

Diesendruck, G., \& Menahem, R. (2015). Essentialism promotes children's inter-ethnic bias. Frontiers in Psychology, 6, Article 1180. https://doi.org/10.3389/fpsyg.2015.01180

Firebaugh, G., \& Davis, K. E. (1998). Trends in antiblack prejudice, 1972-1984: Region and cohort effects. American Journal of Sociology, 94, 251-272. 
Foster-Hanson, E., Leslie, S.J., \& Rhodes, M. (2019, January 20). Speaking of kinds: How generic language shapes the development of category representations. https://doi.org/10.31234/osf.io/28qf7

Frank, M.C. (2019, August 20). Towards a more robust and replicable science of infant development. https://doi.org/10.1016/j.infbeh.2019.101349

Frank, M. C., Bergelson, E., Bergmann, C., Cristia, A., Floccia, C., Gervain, J., ... Yurovsky, D. (2017). A Collaborative Approach to Infant Research: Promoting Reproducibility, Best Practices, and Theory-Building. Infancy. https://doi.org/10.1111/infa.12182.

Gaither, S. E., Schultz, J. R., Pauker, K., Sommers, S. R., Maddox, K. B., \& Ambady, N. (2014). Essentialist thinking predicts decrements in children's memory for racially ambiguous faces. Developmental Psychology, 50(2), 482.

Gelman, S.A. (2003). The Essential Child: Origins of Essentialism in Everyday Thought. New York, NY: Oxford University Press. doi:10.1093/acprof:oso/9780195154061.001.0001.

Gelman, S. A., Coley, J. D., Rosengren, K., Hartman, E., \& Pappas, A. (1998). Beyond labeling: The role of maternal input in the acquisition of richly-structured categories. Monographs of the Society for Research in Child Development. Serial No. 253, Vol. 63, No. 1.

Gelman, S. A., \& Markman, E. M. (1986). Categories and induction in young children. Cognition, 23(3), 183-209. https://doi.org/10.1016/0010-0277(86)90034-X

Gelman, S. A., \& Raman, L. (2003). Preschool children use linguistic form class and pragmatic cues to interpret generics. Child Development, 74(1), 308-325.

Gelman, S. A., \& Rhodes, M. (2012). "Two-Thousand Years of Stasis": How Psychological Essentialism Impedes Evolutionary Understa. In Evolution Challenges: Integrating 
Research and Practice in Teaching and Learning about Evolution Oxford University Press. https://doi.org/10.1093/acprof:oso/9780199730421.003.0001

Gelman, S. A., \& Roberts, S. O. (2017). How language shapes the cultural inheritance of categories. Proceedings of the National Academy of Sciences of the United States of America. https://doi.org/10.1073/pnas.1621073114

Gelman, S. A., \& Tardif, T. (1998). A cross-linguistic comparison of generic noun phrases in English and Mandarin. Cognition, 66(3), 215-248.

Gelman, S. A., Taylor, M. G., Nguyen, S. P., Leaper, C., \& Bigler, R. S. (2004). Mother-child conversations about gender: Understanding the acquisition of essentialist beliefs. Monographs of the Society for Research in Child Development.

Gelman, S.A., Ware, E.A., Kleinberg, F. (2010). Effects of generic language on category content and structure. Cognitive Psychology, 61, 273-301.

Gelman, S. A., \& Wellman, H. M. (1991). Insides and essences: Early understandings of the non-obvious. Cognition. https://doi.org/10.1016/0010-0277(91)90007-Q

Gilmore, R. O., Kennedy, J. L., \& Adolph, K. E. (2018). Practical Solutions for Sharing Data and Materials From Psychological Research. Advances in Methods and Practices in Psychological Science. https://doi.org/10.1177/2515245917746500

Haslam, N., Rothschild, L., \& Ernst, D. (2000). Essentialist beliefs about social categories. British Journal of Social Psychology, 39, 113-127.

Haslam, N., Rothschild, L., \& Ernst, D. (2002). Are essentialist beliefs associated with prejudice? British Journal of Social Psychology, 41, 87-100.

Hirschfeld, L.A. (1996). Race in the Making: Cognition, Culture, and the Child's Construction of Human Kinds. Cambridge, MA: MIT Press. 
Jaswal, V. K., \& Neely, L. A. (2006). Adults Don’t Always Know Best: Preschoolers Use Past Reliability Over Age When Learning New Words. Psychological Science, 17(9), 757-758. https://doi.org/10.1111/j.1467-9280.2006.01778.x

Kinzler K.D. \& Dautel, J.B. (2012). Children's essentialist reasoning about language and race. Developmental Science, 15, 131-138.

Leslie, S.J. (2013). Essence and Natural Kinds: When Science Meets Preschooler Intuition. Oxford Studies in Epistemology, 4, 108-165.

Leslie, S.J. (2017). The original sin of cognition: Fear, prejudice and generalization. The Journal of Philosophy, 114(8), 1-29.

Levy, S.R., \& Dweck, C.S. (1999). The impact of children's static versus dynamic conceptions of people on stereotype formation. Child Development, 70, 1163-1180

Lingeman, J., Freeman, C., \& Adolph, K. E. (2014). Datavyu (Version 1.2.2) [Software]. Available from http://datavyu.org

Lourenco, S. F., \& Tasimi, A. (2020, May 7). No Participant Left Behind: Conducting Science During COVID-19. https://doi.org/10.31234/osf.io/r62gc

Mayr, E. (1982). The growth of biological thought: Diversity, evolution, and inheritance. Cambridge, MA: Belknap Press.

Mayr, E. (1988). Toward a new philosophy of biology, observations of an evolutionist. Cambridge: Harvard.

Mandalaywala, T. M., Amodio, D., \& Rhodes, M. (2017). Essentialism promotes racial prejudice by increasing endorsement of social hierarchies. Social Psychological and Personality Science, 9(4), 461-469. 
Mandalaywala, T.M., Fleener, C., \& Maestripieri, D. (2015). Intelligence in nonhuman primates. In Handbook of intelligence (pp. 27-46). Springer, New York, NY.

Mandalaywala, T. M., Lei, R., Benitez, J., \& Rhodes, M. (2020). When status becomes essential: Developmental changes in the expression and consequences of essentialist beliefs about status.

Mandalaywala, T. M., Ranger-Murdock, G., Amodio, D. M., \& Rhodes, M. (2019). The nature and consequences of essentialist beliefs about race in early childhood. Child Development. 90(4), 437-453.

Moty, K. \& Rhodes, M. (2019, August 29). The unintended consequences of the things we say: What generics communicate to children about unmentioned categories. https://doi.org/10.31234/osf.io/zkjyr.

Nielsen, M., Haun, D., Kärtner, J., \& Legare, C. H. (2017). The persistent sampling bias in developmental psychology: A call to action. Journal of Experimental Child Psychology, 162, 31-38.

Noyes, A., \& Keil, F. C. (2019). Generics designate kinds but not always essences. Proceedings of the National Academy of Sciences of the United States of America. https://doi.org/10.1073/pnas.1900105116

Noyes, A., Keil, F. C. (2020). There is no privileged link between kinds and essences early in development. Proceedings of the National Academy of Sciences of the United States of America. https://doi.org/10.1073/pnas.2003627117

Pauker, K., Ambady, N., \& Apfelbaum, E. (2010). Race salience and essentialist thinking in racial stereotype development. Child Development, 81, 1799-1813.

Pauker, K., Tai, C., \& Ansari, S. (2020). Contextualizing the development of social essentialism. 
Pehrson, S., Brown, R., \& Zagefka, H. (2009). When does national identification lead to the rejection of immigrants? Cross-sectional and longitudinal evidence for the role of essentialist in-group definitions. British Journal of Social Psychology.

\section{https://doi.org/10.1348/014466608X288827}

Plaut, V. C. (2002). Cultural models of diversity in America: The psychology of difference and inclusion.

Prentice D.A., Miller, D.T. (2007). Psychological essentialism of human categories. Current Directions in Psychological Science, 16, 202-206.

Rhodes, M. (2020). Does It Matter How We Speak About Social Kinds? A Large, PreRegistered, Online Experimental Study of How Language Shapes the Development of Essentialist Beliefs. Databrary. Retrieved October 12, 2020 from [blinded for peer review].

Rhodes, M., Cardarelli, A., \& Leslie, S. J. (2020). Asking young children to "do science” instead of "be scientists" increases science engagement in a randomized field experiment. Proceedings of the National Academy of Sciences of the United States of America, 117(18), 9808-9814. https://doi.org/10.1073/pnas.1919646117

Rhodes M. \& Gelman S.A. (2009). A developmental examination of the conceptual structure of animal, artifact, and human social categories across two cultural contexts. Cognitive Psychology, 59, 244-274.

Rhodes, M., Gelman, S. A., \& Karuza, J. C. (2014). Preschool ontology: The role of beliefs about category boundaries in early categorization. Journal of Cognition and Development, 15(1), 78-93.

Rhodes, M., Leslie, S. J., Bianchi, L., \& Chalik, L. (2017). The role of generic language in the early development of social categorization. Child Development, 89(1). 148-155. 
Rhodes, M., Leslie, S. J., Saunders, K., Dunham, Y., \& Cimpian, A. (2017). How does social essentialism affect the development of inter-group relations? Developmental Science, 21, e12509.

Rhodes, M., Leslie, S.J., \& Tworek, C.M. (2012). Cultural transmission of social essentialism. Proceedings of the National Academy of Science, 109, 13526-13531.

Rhodes, M., Leslie, S.J., Yee, K., and Saunders, K. (2019). Subtle linguistic cues increase girls' engagement in science. Psychological Science, 30(3). 455-466.

Rhodes, M., \& Mandalaywala, T. M. (2017). The development and developmental consequences of social essentialism. WIREs Cognitive Science 2017, 8:e1437. doi: 10.1002/wcs.1437

Rhodes, M., \& Moty, K. (2020). What is social essentialism and how does it develop?.

Rizzo, M. T., Elenbaas, L., \& Vanderbilt, K. E. (2020). Do children distinguish between resource inequalities with individual versus structural origins?. Child Development, 91(2), 439-455.

Roberts, S. O., \& Gelman, S. A. (2016). Can white children grow up to be black? Children's reasoning about the stability of emotion and race. Developmental Psychology. https://doi.org/10.1037/dev0000132

Roberts, S., Ho, A., Rhodes, M., \& Gelman, S.A. (2017). Making boundaries great again? Essentialism and support for boundary enhancing initiatives. Personality and Social Psychology Bulletin, 43, 1643-1658.

Rothbart, M., \& Taylor, M. (1992). Category labels and social reality: Do we view social categories as natural kinds? Language, Interaction and Social Cognition.

Rubio-Fernández, P. (2019). Publication standards in infancy research: Three ways to make Violation-of-Expectation studies more reliable. Infant Behavior and Development. https://doi.org/10.1016/j.infbeh.2018.09.009 
Saul, J. (2017). Implicit bias, stereotype threat, and epistemic injustice. In The Routledge Handbook of Epistemic Injustice. https://doi.org/10.4324/9781315212043

Scott, K., \& Schulz, L. (2017). Lookit (Part 1): A new online platform for developmental research. Open Mind: Discoveries in Cognitive Science, 1(1), 4-14. doi:10.1162/opmi_a_00002

Scott, K., Chu, J., \& Schulz, L. (2017). Lookit (Part 2): Assessing the viability of online development research, results from three case studies. Open Mind: Discoveries in Cognitive Science, 1(1), 15-29. doi:10.1162/opmi_a_00001

Segall G., Birnbaum, D., Deeb, I., \& Diesendruck, G. (2015). The intergenerational transmission of ethnic essentialism: how parents talk counts the most. Developmental Science, 18, 543555.

Sheskin, M., Scott, K., Mills, C. M., Bergelson, E., Bonawitz, E., Spelke, E. S., ... \& JaraEttinger, J. (2020). Online Developmental Science to Foster Innovation, Access, and Impact. Trends in Cognitive Sciences.

Shtulman, A., \& Schulz, L. (2008). The relation between essentialist beliefs and evolutionary reasoning. Cognitive science, 32(6), 1049-1062. https://doi.org/10.1080/0364021080189786

Smyth, K., Feeney, A., Eidson, R. C., \& Coley, J. D. (2017). Development of essentialist thinking about religion categories in Northern Ireland (and the United States). Developmental Psychology. https://doi.org/10.1037/dev0000253

Taylor, M. G. (1996). The development of children's beliefs about social and biological aspects of gender differences. Child Development, 67(4), 15551571. https://doi.org/10.2307/1131718 
Taylor, M. G., Rhodes, M., \& Gelman, S. A. (2009). Boys will be boys; Cows will be cows: Children's essentialist reasoning about gender categories and animal species. Child development, 80(2), 461-481. https://doi.org/10.1111/j.1467-8624.2009.01272.x

Vasilyeva, N., Gopnik, A., \& Lombrozo, T. (2018). The development of structural thinking about social categories. Developmental Psychology. https://doi.org/10.1037/dev0000555

Yzerbyt, V., Corneille, O., \& Estrada, C. (2001). The Interplay of Subjective Essentialism and Entitativity in the Formation of Stereotypes. Personality and Social Psychology Review, 5(2), 141-155. https://doi.org/10.1207/S15327957PSPR0502_5

Waxman, S., Medin, D., \& Ross, N. (2007). Folkbiological reasoning from a cross-cultural developmental perspective: Early essentialist notions are shaped by cultural beliefs. Developmental Psychology. https://doi.org/10.1037/0012-1649.43.2.294

Wood, S. M. W., \& Wood, J. N. (2019). Using automation to combat the replication crisis: A case study from controlled-rearing studies of newborn chicks. Infant Behavior and Development. https://doi.org/10.1016/j.infbeh.2019.101329 


\section{Tables and Figures}

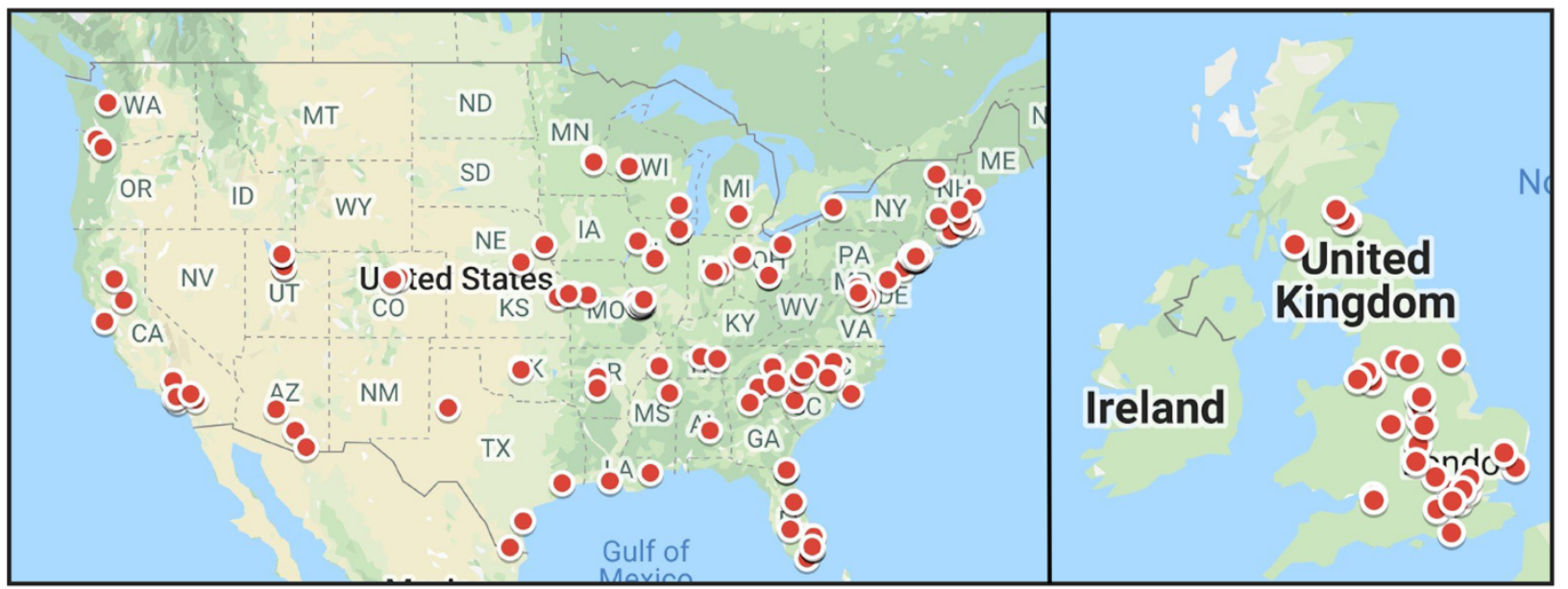

Figure 1.

Figure 1. Regional diversity of participants across the United States and United Kingdom.

Figure 2.

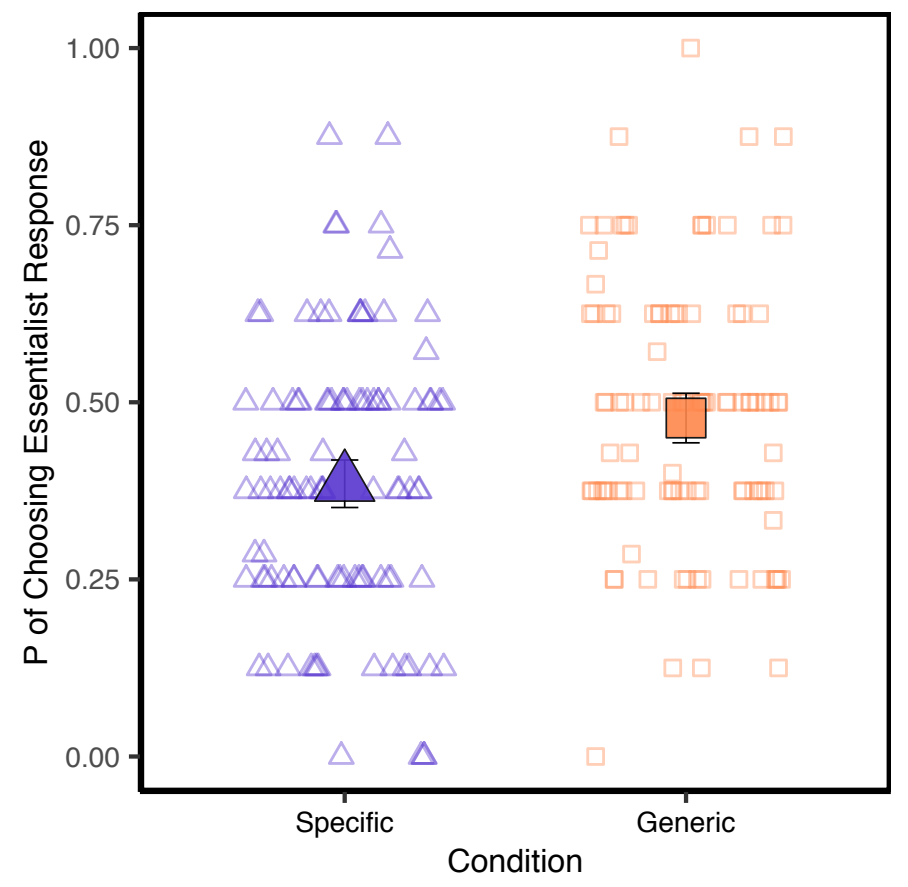

Figure 2. Participants' responses on the essentialism composite as a function of condition $\left(M_{\text {specific }}=.38\right.$; $\left.M_{\text {generic }}=.48\right)$. Error bars represent $95 \%$ confidence intervals.
Figure 3.

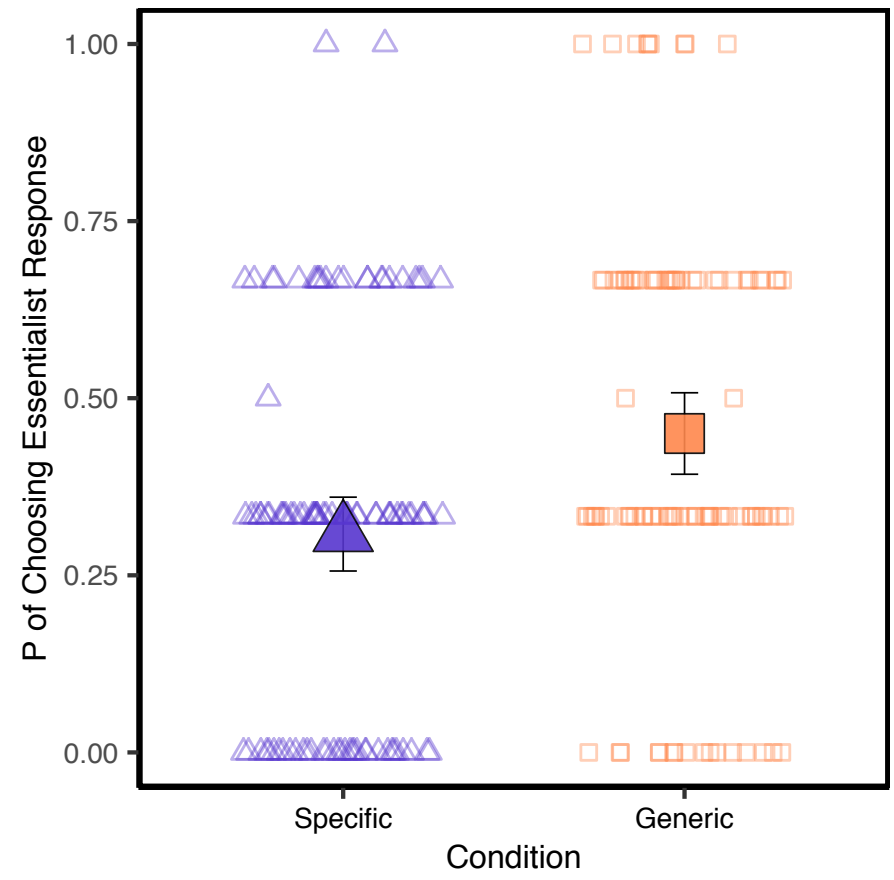

Figure 3. Participants' responses on the explanation items as a function of condition $\left(M_{\text {specific }}=.31 ; M_{\text {generic }}\right.$ $=.45)$. Error bars represent $95 \%$ confidence intervals. 
Figure 4.

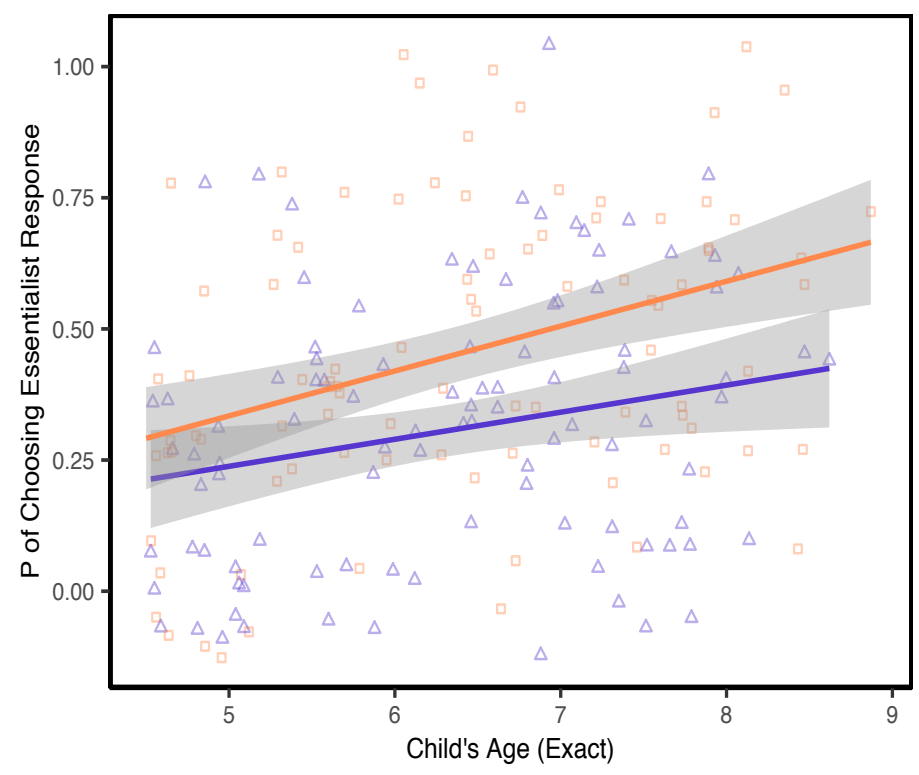

Figure 4. Participants' responses on the explanation items as a function of condition and age. Shaded regions represent $95 \%$ confidence intervals.

Figure 6.

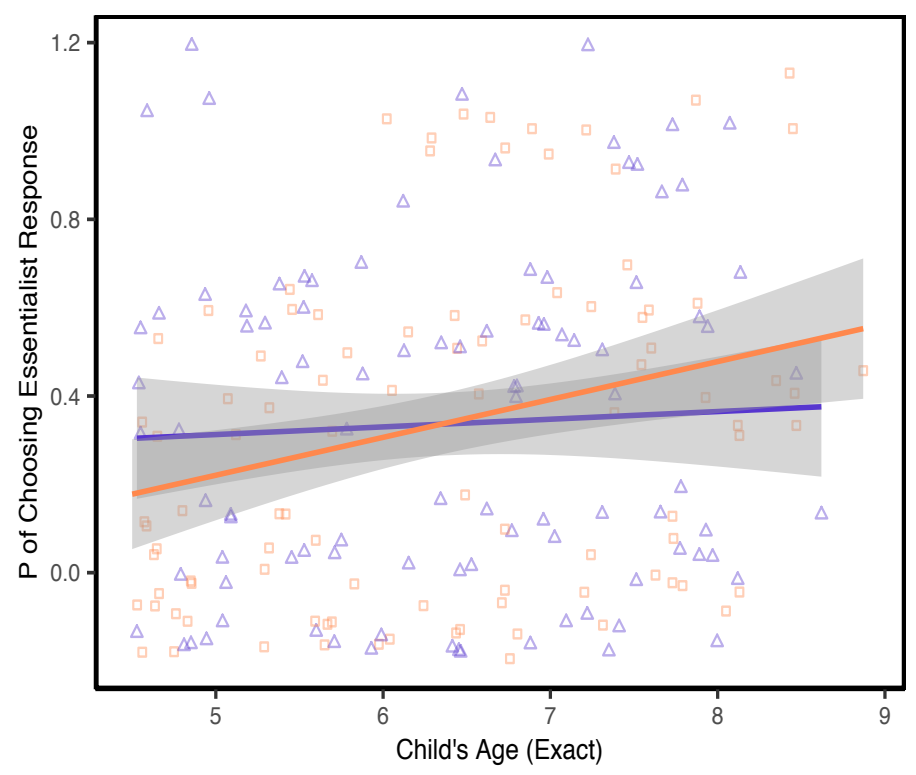

Figure 6. Participants' responses on the inheritance items as a function of condition and age. Shaded regions represent $95 \%$ confidence intervals.

\section{Figure 5.}

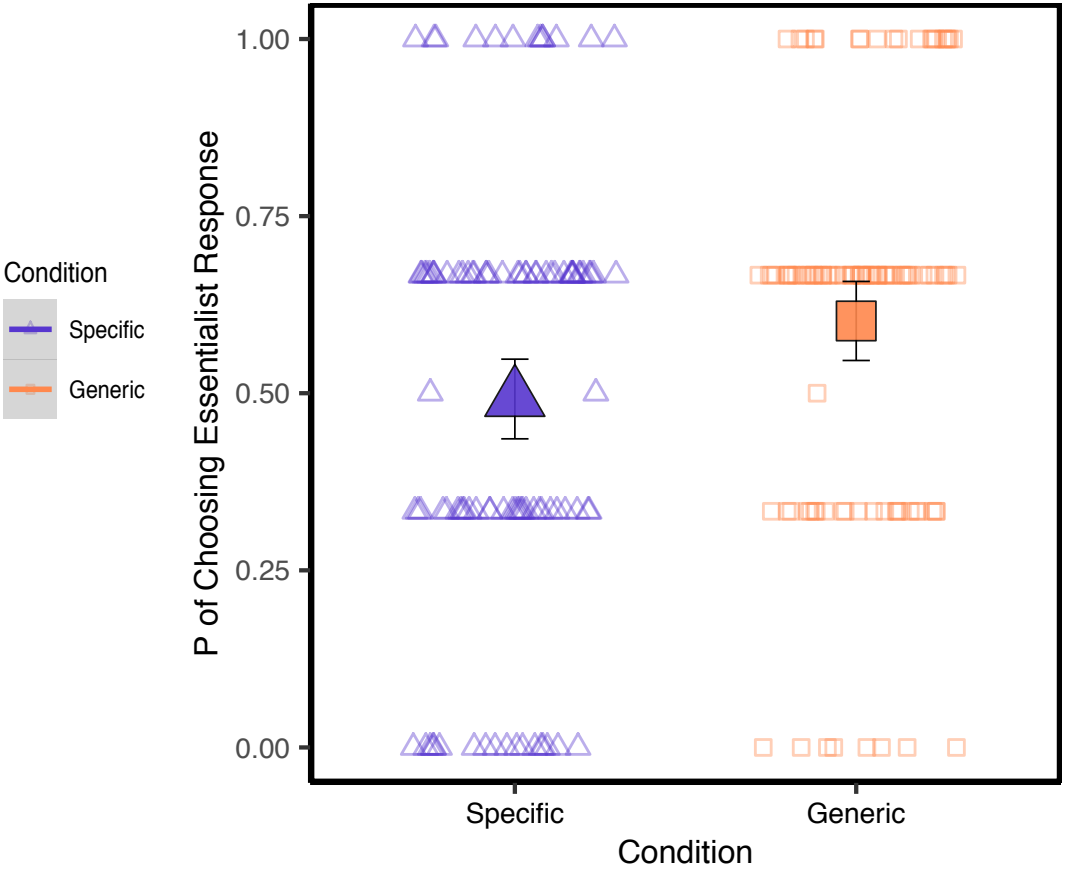

Figure 5. Participants' responses on the flexibility items as a function of condition $\left(M_{\text {specific }}=.49 ; M_{\text {generic }}\right.$ $=.60$ ). Error bars represent $95 \%$ confidence intervals.

\section{Figure 7.}

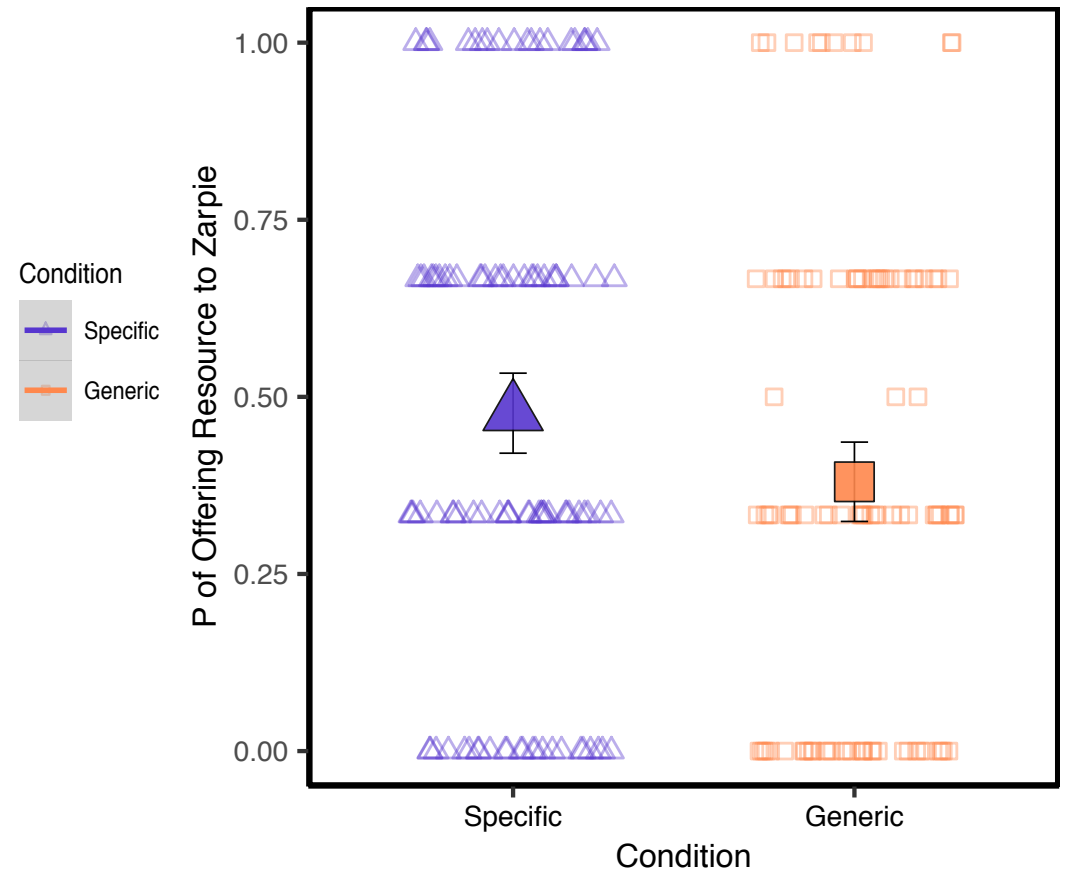

Figure 7. Participants' likelihood of allocating resources to Zarpies as a function of condition $\left(M_{\text {specific }}=.48 ; M_{\text {generic }}=38\right)$. Error bars represent $95 \%$ confidence intervals. 


\section{Figure Captions}

Figure 1. Regional diversity of participants across the United States and United Kingdom.

Figure 2. Participants' responses on the essentialism composite as a function of condition $\left(M_{\text {specific }}=.38 ; M_{\text {generic }}=.48\right)$. Error bars represent $95 \%$ confidence intervals.

Figure 3. Participants' responses on the explanation items as a function of condition $\left(M_{\text {specific }}=\right.$ $\left..31 ; M_{\text {generic }}=.45\right)$. Error bars represent $95 \%$ confidence intervals.

Figure 4. Participants' responses on the explanation items as a function of condition and age. Shaded regions represent $95 \%$ confidence intervals.

Figure 5. Participants' responses on the flexibility items as a function of condition $\left(M_{\text {specific }}=\right.$ $\left..49 ; M_{\text {generic }}=.60\right)$. Error bars represent $95 \%$ confidence intervals.

Figure 6. Participants' responses on the inheritance items as a function of condition and age. Shaded regions represent $95 \%$ confidence intervals.

Figure 7. Participants' likelihood of allocating resources to Zarpies as a function of condition $\left(M_{\text {specific }}=.48 ; M_{\text {generic }}=.38\right)$. Error bars represent $95 \%$ confidence intervals. 